\title{
Clinical and Epidemiological Characteristics of
} Acute Poisoning in Children in Southwestern China:
A Review of 1755 Cases from 2014 to 2020

\begin{abstract}
Qiang Dai, ${ }^{1,2}$ Li Wang, 2
XiangYu Gao,' Donghong Du, ${ }^{3}$

Peiyuan Shuai, ${ }^{4}$ Lei Li, ${ }^{5}$

Wenjun Liu (iD)

'Department of Pediatrics, Affiliated Hospital of Southwest Medical University, Sichuan Clinical Research Center for Birth Defects, Luzhou, 64600, Sichuan, People's Republic of China; ${ }^{2}$ Department of Pediatrics, People's Hospital of Leshan, Leshan, 614000, Sichuan, People's Republic of China; ${ }^{3}$ Department of Pediatrics, People's Hospital of Emeishan, Emeishan, 614200, Sichuan, People's Republic of China; ${ }^{4}$ Department of Pediatrics, People's Hospital of Qianwei, Qianwei, 614400, Sichuan, People's Republic of China; ${ }^{5}$ Department of Pediatrics, People's Hospital of Mabian, Mabian, 6I4600, Sichuan, People's Republic of China
\end{abstract}

\section{Video abstract}

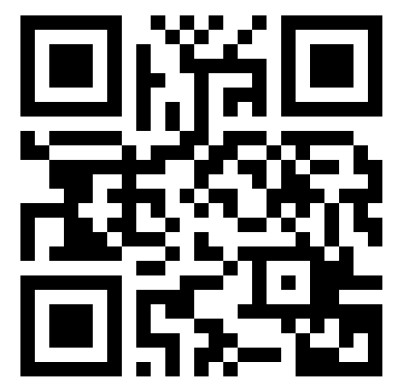

Point your SmartPhone at the code above. If you have a QR code reader the video abstract will appear. Or use: https://youtu.be/swsd9k16XE

Correspondence: Wenjun Liu

Department of Pediatrics, Affiliated Hospital of Southwest Medical University, Sichuan Clinical Research Center for Birth Defects, Luzhou, 64600, Sichuan, People's Republic of China

Tel +86 I39802590I2

Email wenjun_liu@swmu.edu.cn
Purpose: Acute poisoning is a major cause of disability and death in children, but there is a lack of large-scale and multicenter epidemiological data on acute poisoning in children.

Patients and Methods: The current study was a retrospective analysis of clinical data from 1755 children aged 0 to 14 years who were hospitalized between 01 January 2014 and 31 December 2020 in southwestern China.

Results: Acute poisoning was common in childhood, particularly in early childhood (607; $34.6 \%)$ and preschool $(655 ; 37.3 \%)$, and most cases occurred in rural areas $(1191 ; 67.9 \%)$. It was more common in boys $(934 ; 53.2 \%)$ than in girls $(821 ; 46.8 \%)$. In urban areas, poisoning was mainly caused by drugs $(266 ; 47.2 \%)$, chemical agents $(59 ; 10.5 \%)$, and alcohol $(54 ; 9.6 \%)$. In rural areas, it was mainly caused by pesticides $(620 ; 52.1 \%)$ and medications $(213 ; 17.9 \%)$, the route of poisoning was usually the digestive tract $(1671$; $95.2 \%)$, in most cases the poisoning was accidental $(1618 ; 92.3 \%)$, and pesticides $(659$; $37.5 \%$ ) and medications $(479 ; 27.3 \%)$ predominated. After timely treatment, the majority of patients had no substantial organ damage, sequelae, or disabilities, and mortality was low $(17 ; 1.0 \%)$.

Conclusion: Acute poisoning is a frequent accident in childhood, mainly in infants and preschool children, mostly in rural areas, and poisoning mostly occurs via the digestive tract. Family and community education should be conducted to prevent poisoning.

Keywords: acute, children, poisoning, prevalence

\section{Introduction}

Acute poisoning in children is a major public health problem worldwide. ${ }^{1-3}$ It has become the main factor that harms children and leads to disability and death of children. It is one of the four main causes of accidental death of children. ${ }^{4}$ Since the beginning of the last century, with the development of agriculture and industry, morbidity and mortality associated with child poisoning have gradually increased worldwide. In the past 20 years the global incidence of acute child poisoning was $1.8 / 100,000 .^{5}$ The mortality rate in low-income countries is four times higher than that in developed countries. ${ }^{6}$ Due to their living environment, growth and development, and physiological and dietary factors, children are extremely sensitive to poisons, which can cause varying degrees of damage to their organs and can lead to death. To date, only a small number of large-scale, multicenter, epidemiological studies on acute childhood poisoning have been reported, and the epidemiology of acute childhood poisoning differs in different countries and regions. ${ }^{7}$ The total 
population of southwestern China is approximately 265 million, ${ }^{8}$ and the population is unevenly distributed. Economic and educational levels are relatively low. In the current study, clinical data derived from 1755 children admitted to participating hospitals in southwestern China between 01 January 2014 and 31 December 2020 were acquired. The data were systematically retrospectively analyzed to investigate clinical and epidemiological characteristics of acute poisoning in children.

\section{Materials patients and Methods Patients}

Clinical records of 1755 children aged 0-14 years hospitalized at one of four institutions between 01 January 2014 and 31 December 2020 were reviewed. The diagnostic criteria for acute poisoning were consistent with an expert consensus $^{9}$ and the International Classification of Diseases (ICD) code ICD-11. ${ }^{10}$ Children with chronic poisoning, non-acute poisoning, no clear toxic poison, and incomplete clinical data were excluded from the study. The study is a retrospective study. The patient's important private information was effectively de-identified and effectively protected. The remaining medical information was approved by the institutional review board of the Affiliated Hospital of Southwest Medical University, the People's Hospital of Leshan, the People's Hospital of Emeishan, the People's Hospital of Qianwei, the People's Hospital of Mabian, and the requirement for informed consent was waived. At the same time, we declare to protect patient privacy information, comply with the laws protecting patient privacy, and comply with the Declaration of Helsinki.

\section{Methods}

Each hospital's digital information management medical records were systematically reviewed and relevant cases were screened using the exclusion criteria to extract the gender, age, and clinical data of children with acute poisoning. The age groups collated were infants $(<1$ year), early childhood (1-3 years), preschool (4-6 years), school-aged (7-12 years), and adolescent (13-14 years). Living environment was classified as rural or town, and the seasons in which the cases occurred were tabulated, as were the types of poisons involved, duration of treatment after poisoning, route of poisoning, complications, and prognoses. According to T36-T65 in the ICD-11 code, ${ }^{9}$ poison substances are divided into pesticides, medications, food (including toadstools, spoiled food, and improperly processed food, among others), chemical agents (such as food desiccant, laundry detergent, and potassium permanganate solution), carbon monoxide (CO), alcohol, bee stings, foreign objects (such as glass balls, toys, and jewelry), coins, and heavy metals (mercury and lead). Condition at the time of discharge is the primary indicator of curative effect, where (1) "cure" refers to no clinical manifestations and no abnormal physiological or biochemical indicators; (2) "improvement" refers to clinical manifestations alleviated, and physiological and biochemical indicators improved, but not completely normal; (3) "unhealed" refers to clinical manifestations and physiological and biochemical indicators not being significantly improved, or worsening, giving up treatment and being discharged; and (4) "death" refers to certified clinical death. The effective rate is the cure rate plus the improvement rate.

\section{Statistical Analysis}

The Death Statistics Database and the Occupational Disease Monitoring and Reporting System database use the eleventh edition of the International Classification of Diseases (ICD-11) coding system. ${ }^{9}$ These data were entered into Microsoft Office Excel, and GraphPad Prism (8.0) statistical software was also used. Classification variables (age group, gender, living environment, poison type, poisoning route, time of poisoning visits, monthly and annual distribution of male and female admissions, prognostic distribution) were used to derive component ratios $(\%)$. The $\chi^{2}$ test, $t$-test, or Fisher's exact probability method were used for statistical analyses, and $p<0.05$ was considered statistically significant.

\section{Results}

\section{General Information}

Of the 1755 children, 934 (53.2\%) were boys and 821 $(46.8 \%)$ were girls, the mean age was $5.05 \pm 3.76$ years and the median age was 3.4 years, and there were 1191 $(67.9 \%)$ in rural areas and $564(32.1 \%)$ in urban areas. There were 55 patients (3.1\%) in the infant group, 607 $(34.6 \%)$ in the early childhood group, 655 (37.3\%) in the preschool group, $235(13.4 \%)$ in the school age group, and $203(11.6 \%)$ in the adolescent group. Early childhood and preschool age accounted for the main. $\left(\chi^{2}=160.3, p<\right.$ $0.01)$. Male were 6.4 years old and female were 6.1 years old, and the difference was not statistically significant 
( $t=0.34, P=0.73$ ). Poisonings occurred in all four seasons, and there were slightly more in spring (28.7\%) (Table 1$)$.

\section{Types of Poisoning}

Among the 1755 children, there were 659 cases (37.5\%) of pesticide poisoning (paraquat, dichlorvos, methyl parathion, methamidophos, pyrethroid insecticides), 479 $(27.3 \%)$ of medication poisoning (including aminophylline, lorazepam, carbamazepine, birth control pills, and montelukastner), 161 (9.2\%) of food poisoning, 109 $(6.2 \%)$ of rodenticide poisoning, $121(6.9 \%)$ of chemical poisoning, $49(2.8 \%)$ of $\mathrm{CO}$ poisoning, $80(4.6 \%)$ of alcohol poisoning, $11(0.6 \%)$ of bee stings, and 86 $(4.9 \%)$ of other foreign bodies (including coins, heavy metals, glass beads, and plastic toys). Eleven cases $(0.6 \%)$ resulted in death, and most of these involved pesticide poisoning. Most of the drug poisoning cases involved prescription drugs such as anti-hypertensive drugs, diabetes drugs, psychotropic drugs, anti-allergic drugs, contraceptives, and commonly used cold drugs. Most of the pesticide poisonings involved organophosphorus pesticides and herbicides. Food poisonings were mainly due to spoiled food, toadstool poisoning, and poisonous plants that are not suitable for children to eat such as ginkgo biloba. Children in infancy and early childhood mainly presented with drug poisoning, preschool children mainly presented with drug and pesticide poisoning, and school-aged and adolescent children mainly presented with pesticide poisoning $\left(\chi^{2}=60.53, p<0.01\right)$. Pesticides and medication poisonings predominated in both boys and girls, followed by food, chemical agents, alcohol, rodent poison, and other toxicants. In urban children medications and chemical agents predominated, whereas in rural children pesticides and medications predominated $(p<0.01)$. In all seasons poisonings by pesticides and medications were the most common. There were 161 cases $(9.2 \%)$ of food poisoning, including 48 (29.8\%) in summer and 68 $(41.6 \%)$ in summer and autumn. There were 89 cases $(55.3 \%)$ of eating spoiled food, and $26(16.1 \%)$ of oral toadstool poisoning. The southwestern region has a hilly climate, and mushrooms grow vigorously in summer and autumn, causing increased mushroom poisoning. 41 cases (83.7\%) of $\mathrm{CO}$ poisoning occurred in spring and winter, including 10 cases $(24.3 \%)$ in spring and 31 cases $(75.6 \%)$ in winter and the difference was statistically significant $\left(\chi^{2}\right.$ $=45.45, p<0.01)$. Among children of Yi nationality 138 $(85.2 \%)$ were poisoned by pesticides, which differed significantly from the corresponding number of Han children $\left(\chi^{2}=172.7, p<0.01\right)$. Of the four seasons, the most cases of poisoning were reported in spring $(504 ; 28.7 \%)$, and the difference was statistically significant $\left(\chi^{2}=11.7, p<0.05\right)$ (Table 1). The total of 1755 cases of poisoning included 80 cases $(4.6 \%)$ of alcohol poisoning. In 63 of these 80 cases (78.8\%) the patient was an adolescent. In 54/80 cases (67.5\%) the poisoning was acute. In $63 / 80$ cases $(78.8 \%)$ the patient engaged in occasional heavy drinking, in $9 / 80$ cases $(11.3 \%)$ the patient had only used alcohol twice, and in $9 / 80$ cases $(11.3 \%)$ the patient was a school-aged child who occasionally drank a lot of alcohol (Table 2).

\section{Routes and Causes of Poisoning}

The total of 1755 poisonings included 978 cases (55.7\%) of accidental poisoning, 479 (27.3\%) of drug poisoning, $161(9.2 \%)$ of food poisoning, $53(3.0 \%)$ of intentional poisoning, 49 (2.8\%) of inhalation poisoning, 21 (1.2\%) of contact poisoning, $11(0.6 \%)$ of Animal bite stabbing, and $3(0.4 \%)$ of iatrogenic poisoning. Most cases in both urban and rural children involved accidentally taking poisons or drugs, or food poisoning $\left(\chi^{2}=4.875, p<0.05\right)$. The main poisoning route in infancy, early childhood, preschool, and school-aged children was accidental ingestion, with a total of 1477 cases (84.2\%). A total of 194 patients (11.1\%) were poisoned via accidental ingestion of drugs or unsanitary food. Forty-three cases (21.2\%) of intentional poisoning during adolescence accounted for $81.1 \%$ of the total number of intentional poisonings $\left(\chi^{2}=424.2, p<\right.$ $0.01)$. There were seasonal changes in the numbers of pesticide poisoning cases. In the four seasons, accidental poisoning was the main cause, and the proportion of poisoning increased in autumn and winter $\left(\chi^{2}=46.66\right.$, $p<0.01)$. There were 41 cases $(83.7 \%)$ of inhalation poisoning in spring and winter, indicating that the incidence rate went up significantly. There were 134 cases $(82.7 \%)$ of accidental poisoning in Yi children, and 16 cases $(9.9 \%)$ of intentional poisoning, which differed significantly from Han children $\left(\chi^{2}=77.73, p<0.01\right)$ (Table 3).

\section{Monthly and Annual Distributions of Acute Poisoning in Children}

Child poisoning was most common in March, with 209/ 1755 cases $(11.9 \%)$, which may be related to spring plowing and planting factors $\left(\chi^{2}=7.76, p<0.735\right)$. There were relatively few cases in April and July, each with 124 (7.1\%) (Figure 1). In the years 2014-2020, the numbers 
Table I Composition of Toxicants in 1755 Children with Acute Poisoning with Different Characteristics

\begin{tabular}{|c|c|c|c|c|c|c|c|c|c|c|c|c|}
\hline Group & & $\begin{array}{l}\text { Pesticides, } \\
\text { n (\%) }\end{array}$ & $\begin{array}{l}\text { Medicines, } \\
\text { n (\%) }\end{array}$ & $\begin{array}{l}\text { Food, } \\
\text { n (\%) }\end{array}$ & $\begin{array}{l}\text { Rat Poison, } \\
\text { n (\%) }\end{array}$ & $\begin{array}{c}\text { Chemicals, } \\
\text { n (\%) }\end{array}$ & $\begin{array}{c}\text { co, } \\
\text { n (\%) }\end{array}$ & $\begin{array}{c}\text { Alcohol, } \\
\text { n (\%) }\end{array}$ & $\begin{array}{c}\text { Animal Bite Stabbing, } \\
\text { n (\%) }\end{array}$ & $\begin{array}{l}\text { Other, } \\
\text { n (\%) }\end{array}$ & $\chi^{2}$ & $P$ value \\
\hline \multirow[t]{2}{*}{ Gender } & Male & $311(33.2)$ & $255(27.3)$ & $\begin{array}{c}100 \\
(10.7)\end{array}$ & $65(6.9)$ & $66(7.1)$ & $25(2.7)$ & $60(6.4)$ & $6(0.6)$ & $46(4.9)$ & - & $<0.0001$ \\
\hline & Female & $348(42.4)$ & $224(27.3)$ & 61 (7.4) & $44(5.4)$ & $55(6.7)$ & $24(2.9)$ & $20(2.4)$ & $5(0.6)$ & $40(4.9)$ & & \\
\hline \multirow[t]{2}{*}{ Live } & Rural area & $620(52.1)$ & $213(17.9)$ & $108(9.1)$ & $93(7.8)$ & $62(5.2)$ & $33(2.8)$ & $26(2.2)$ & $8(0.7)$ & $28(2.4)$ & - & $<0.0001$ \\
\hline & Town & $39(5.7)$ & $266(47.2)$ & $53(9.4)$ & $16(2.8)$ & $59(10.5)$ & $16(2.8)$ & $54(9.6)$ & $3(0.5)$ & $58(10.3)$ & & \\
\hline \multirow[t]{5}{*}{ Age } & Infancy & $7(12.7)$ & $24(43.6)$ & $3(5.5)$ & $7(12.7)$ & $9(16.4)$ & $2(3.6)$ & 0 & I (I.8) & $2(3.6)$ & 60.53 & $<0.0001$ \\
\hline & $\begin{array}{c}\text { Early } \\
\text { childhood }\end{array}$ & I5I (24.9) & 227 (37.4) & $27(4.4)$ & $57(9.4)$ & 77 (I2.7) & $6(1.0)$ & $4(0.6)$ & I (0.2) & $57(9.4)$ & & \\
\hline & Preschool & $368(56.2)$ & I 37 (20.9) & $49(7.5)$ & $35(5.3)$ & $21(3.2)$ & $17(2.6)$ & $4(0.6)$ & $2(0.3)$ & $22(3.4)$ & & \\
\hline & School age & $72(30.6)$ & $48(20.4)$ & 65 (27.7) & $6(2.6)$ & $8(3.4)$ & $16(6.8)$ & $9(10.6)$ & $6(2.6)$ & $5(2.1)$ & & \\
\hline & Puberty & $61(30.0)$ & $43(2 \mid .2)$ & $17(8.4)$ & $4(2.0)$ & $6(3.0)$ & $8(4.0)$ & $63(31.0)$ & I $(0.5)$ & 0 & & \\
\hline \multirow[t]{4}{*}{ Season } & Spring & $214(42.5)$ & $148(29.3)$ & $19(3.8)$ & $27(5.4)$ & $38(7.5)$ & $10(2.0)$ & $18(3.6)$ & I $(0.2)$ & $29(5.8)$ & 15.39 & $=0.015$ \\
\hline & Summer & $134(32.2)$ & $129(31.0)$ & 48 (II.5) & $29(7.0)$ & $34(8.2)$ & $4(1.0)$ & $20(4.8)$ & $3(0.7)$ & $15(3.6)$ & & \\
\hline & Autumn & $153(36.3)$ & 91 (21.6) & 67 (15.9) & $30(7.1)$ & $25(5.9)$ & $4(0.9)$ & $21(5.0)$ & $7(1.7)$ & $24(5.7)$ & & \\
\hline & Winter & $158(38.3)$ & III (26.9) & $27(6.5)$ & $23(5.6)$ & $24(5.8)$ & 31 (7.5) & $2 I(5.1)$ & 0 & $18(4.4)$ & & \\
\hline \multirow[t]{2}{*}{ Nationality } & Han & 521 (32.7) & 47I (29.6) & $\begin{array}{c}159 \\
(10.0)\end{array}$ & $108(6.8)$ & 115 (7.2) & $\begin{array}{c}47(3 \\
0.0)\end{array}$ & $75(4.7)$ & II (0.7) & $86(5.4)$ & 172.7 & $<0.0001$ \\
\hline & $Y i$ & I 38 (85.2) & $8(4.9)$ & $2(1.2)$ & I (0.6) & $6(3.7)$ & $2(1.2)$ & $5(3.1)$ & 0 & 0 & & \\
\hline
\end{tabular}


Table 2 Characteristic Distribution of 80 Cases of Alcoholism

\begin{tabular}{|l|c|c|c|c|}
\hline & Early Childhood & Preschool & School Age & Puberty \\
\hline Case & $4(5.0)$ & $4(5.0)$ & $9(11.3)$ & $63(78.8)$ \\
Acute alcoholism & $4(5.0)$ & $4(5.0)$ & $9(11.3)$ & $54(67.5)$ \\
Alcohol use & 0 & 0 & 0 & $9(11.3)$ \\
Occasionally heavy & 0 & 0 & $9(11.3)$ & $63(78.8)$ \\
drinking & & & & \\
\hline
\end{tabular}

of cases increased every year. Poisonings were more frequent in boys than in girls, but the difference was not statistically significant $\left(\chi^{2}=0.82, p<0.84\right)$ (Figure 2).

\section{Clinical Characteristics of Poisonings}

There were 1671 cases of poisoning via the digestive tract, including 85 cases $(5.1 \%)$ with acute liver function impairment. Of 49 cases $(2.8 \%)$ of inhalation poisoning, all exhibited different respiratory and neurological symptoms. Twenty-one patients (1.2\%) were poisoned via contact, mainly involving the circulatory system and other manifestations. There were 11 cases $(0.6 \%)$ of children who were bitten stabbing by animals. All presented with manifestations of the nervous system and other systems, including 2 patients (18.2\%) who exhibited acute renal insufficiency. There were 3 cases $(0.2 \%)$ of iatrogenic poisoning, which mainly manifested as nervous system symptoms. The others were including, skin allergies, infections, acidosis, electrolyte disturbances, local edema, skin rashes (Table 4).

\section{Hospitalization Times}

Of the children who presented with pesticide poisoning, $202(30.7 \%)$ were hospitalized for $\leq 3$ days, $314(47.6 \%)$ for 4-6 days, 76 (11.5\%) for 7-9 days, and 67 (10.2\%) for $\geq 10$ days. Of the children who presented with drug poisoning, $468(97.7 \%)$ were hospitalized for $\leq 3$ days, and $1(0.2 \%)$ was hospitalized for 7 days. Of the children who presented with food poisoning, 141 (87.5\%) were hospitalized for $\leq 3$ days, and $20(12.4 \%)$ were hospitalized for 4-6 days. The hospitalization times of the remaining children in the study were $<3$ days. There was a statistically significant difference in the length of hospitalization between children poisoned by pesticides and drugs $\left(\chi^{2}=515.3, \mathrm{p}<0.05\right)$, and hospitalization times associated with pesticide poisoning were longer than those associated with drugs and other poisons (Table 5).

\section{Follow-Up}

A total of 199 of the 1755 children (11.3\%) were followed up, $186(10.6 \%)$ had ingested poison by mistake and were subsequently cured. Of these, $12(6.0 \%)$ were cases of self-administration of poisons. Such patients were transferred to the psychological counseling clinic for treatment One child died after taking paraquat by mistake.

\section{Discussion}

According to a report from World Health Organization, ${ }^{11}$ acute poisoning is the fourth most common cause of childhood morbidity and mortality. Poisoning has become an important factor affecting child health. The incidence of acute poisoning in children reportedly ranges from $0.3 \%$ to $7.6 \% .^{12}$ The current study suggests that child poisoning in southwestern China is mainly concentrated in the 1-5 years, which is related to specific features of such children; ie, poor cognition, eagerness to explore new things, a lack of awareness of potential dangers, and lack of selfprotection awareness. It has been previously reported that some pesticides are packaged with fruit and vegetable patterns, and some drugs taste good, which increases the risk of child poisoning. ${ }^{13}$

In the current study conducted in southwestern, more boys presented with acute poisoning than girls. Pesticide poisoning was the most common cause in rural areas, and the main poisons were organophosphorus pesticides, insecticides, and herbicides. The main causes in cities were drugs, including anti-hypertensives, sleeping pills, hypoglycemic drugs, antipyretic and analgesic drugs, and anti-allergic drugs, This was related to areas where agriculture was the main production and lifestyle. ${ }^{14-16}$ In most cases, the poisoning was unintentional, a single type of poison was involved, the dose was small, and it did not cause major harm to the child. Many studies indicate that most cases of acute poisoning in children are due to inefficient parental care and are caused by lax storage of poisons. ${ }^{17,18}$ Some cases of drug poisoning are caused by parents who did not carefully read the prescription 
Table 3 Distribution of Causes in 1755 Children with Acute Poisoning with Different Characteristics (n, \%)

\begin{tabular}{|c|c|c|c|c|c|c|c|c|c|c|c|}
\hline Group & & $\begin{array}{l}\text { Accidental } \\
\text { Poisoning }\end{array}$ & $\begin{array}{c}\text { Drug } \\
\text { Poisoning }\end{array}$ & $\begin{array}{c}\text { Food } \\
\text { Poisoning }\end{array}$ & $\begin{array}{l}\text { Inhalation } \\
\text { Poisoning }\end{array}$ & $\begin{array}{l}\text { Contact } \\
\text { Poisoning }\end{array}$ & $\begin{array}{c}\text { Intentional } \\
\text { Poisoning }\end{array}$ & $\begin{array}{l}\text { latrogenic } \\
\text { Poisoning }\end{array}$ & $\begin{array}{c}\text { Animals' Bite } \\
\text { Stabbing }\end{array}$ & $\chi^{2}$ & $P$ value \\
\hline \multirow[t]{2}{*}{ Gender } & Male & $505(54.1)$ & $255(27.3)$ & $100(10.7)$ & $25(2.7)$ & $10(1.1)$ & $30(3.2)$ & $3(0.3)$ & $6(0.6)$ & - & $P=0.0419$ \\
\hline & Female & $473(57.6)$ & $224(27.3)$ & $61(7.4)$ & $24(2.9)$ & II (I.3) & $23(2.8)$ & 0 & $5(0.6)$ & & \\
\hline \multirow[t]{5}{*}{ Age } & Infancy & $24(43.6)$ & $24(43.6)$ & $3(5.5)$ & $2(3.6)$ & 0 & 0 & I (I.8) & I (I.8) & 424.2 & $P<0.0001$ \\
\hline & $\begin{array}{c}\text { Early } \\
\text { childhood }\end{array}$ & $339(55.8)$ & 227 (37.4) & $27(4.4)$ & $6(1.0)$ & $5(0.8)$ & $2(0.3)$ & 0 & I $(0.2)$ & & \\
\hline & Preschool & $446(68.1)$ & I37 (20.9) & $49(7.5)$ & $17(2.6)$ & $3(0.5)$ & 0 & I $(0.2)$ & $2(0.3)$ & & \\
\hline & School age & 78 (33.2) & $48(20.4)$ & 65 (27.7) & $16(6.8)$ & $13(5.5)$ & $8(34.0)$ & I (0.4) & $6(2.6)$ & & \\
\hline & Puberty & 91 (44.8) & $43(2 \mid .2)$ & $17(8.4)$ & $8(4.0)$ & 0 & $43(2 \mid .2)$ & 0 & I $(0.5)$ & & \\
\hline \multirow[t]{2}{*}{ Live } & Rural area & $76 \mid(64.6)$ & $213(17.9)$ & $108(9.1)$ & $33(2.8)$ & $19(1.6)$ & $48(4.0)$ & $I(0.1)$ & $8(2.6)$ & 4.875 & $P=0.0275$ \\
\hline & Town & $217(38.8)$ & $266(47.2)$ & $53(9.4)$ & $16(2.8)$ & $2(0.4)$ & $5(0.9)$ & $2(0.4)$ & $3(0.5)$ & & \\
\hline \multirow[t]{4}{*}{ Season } & Spring & $313(62.0)$ & I 48 (29.3) & $19(3.8)$ & $10(2.0)$ & $3(0.6)$ & $10(2.0)$ & I $(0.2)$ & I $(0.2)$ & 46.66 & $P<0.0001$ \\
\hline & Summer & $219(52.6)$ & $129(31.0)$ & 48 (II.5) & $4(1.0)$ & $8(2.0)$ & $4(1.0)$ & I $(0.3)$ & $3(0.7)$ & & \\
\hline & Autumn & $224(53.2)$ & 91 (21.6) & 67 (15.9) & $4(0.9)$ & 8 (1.9) & $20(4.8)$ & 0 & 7 (I.7) & & \\
\hline & Winter & $222(53.8)$ & III (26.9) & $27(6.5)$ & $31(7.5)$ & $2(0.5)$ & $19(4.6)$ & I $(0.2)$ & 0 & & \\
\hline \multirow[t]{2}{*}{ Nationality } & Han & $844(53.0)$ & 47I (29.6) & $159(10.0)$ & $47(2.9)$ & $21(1.3)$ & $37(2.3)$ & $3(0.2)$ & II (0.7) & 77.73 & $P<0.0001$ \\
\hline & $Y i$ & I34 (82.7) & $8(4.9)$ & $2(1.2)$ & $2(1.2)$ & 0 & $16(9.9)$ & 0 & 0 & & \\
\hline
\end{tabular}




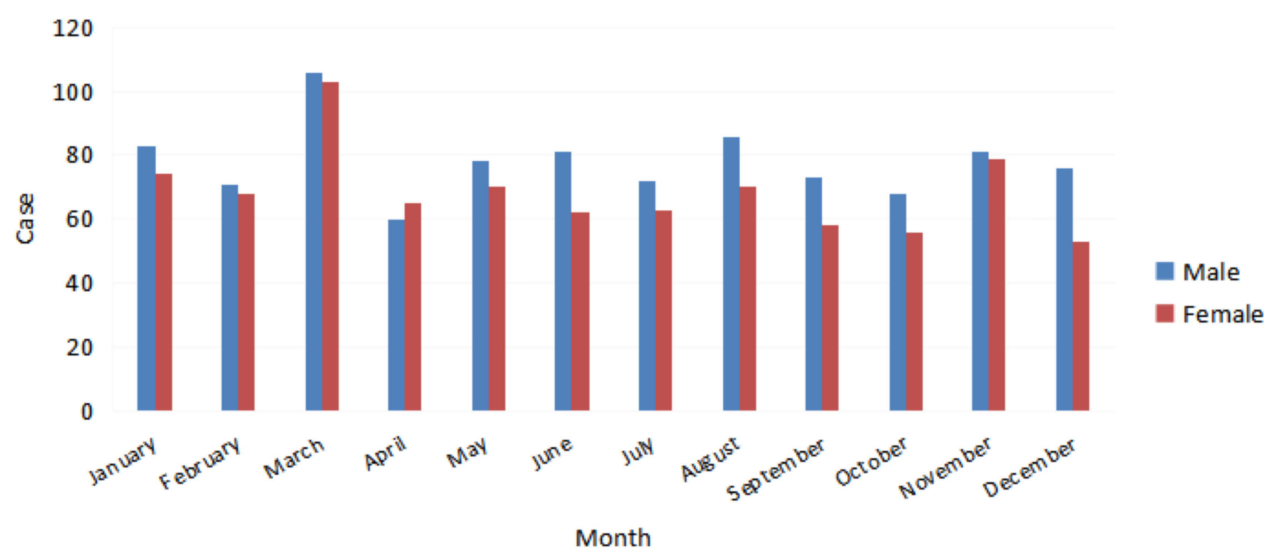

Figure I Monthly distribution of acute poisoning in children.

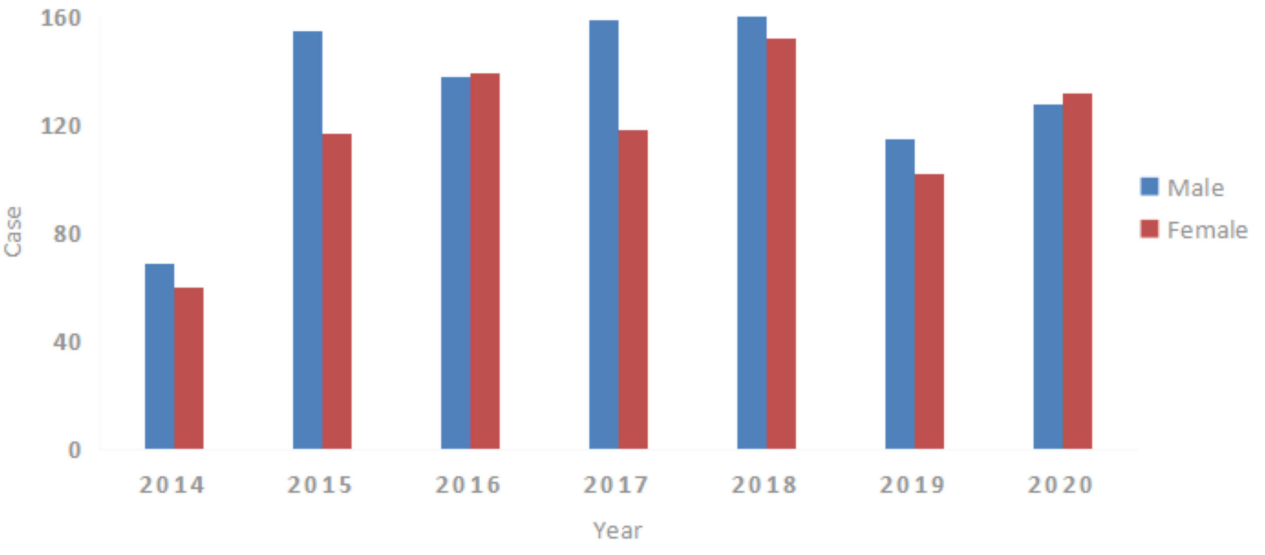

Figure 2 Annual distribution of acute poisoning in children from 2014 to 2020 .

medicine prescribed by the doctor. It is necessary for hospitals and drug manufacturers to improve methods of drug use and management. ${ }^{19}$ With growth in the Social Demographic Index, the rate of $\mathrm{CO}$ poisoning has also increased. ${ }^{20}$ In the present study, $\mathrm{CO}$ poisoning mainly occurred in spring and winter. It was generally related to burning charcoal in a confined space for heating, or an airtight bathroom. Common sense strengthens popular science education. ${ }^{21,22}$ In acutely ill children with ptosis, blurred vision, dizziness and headache, respiratory distress, and unexplained renal failure, the possibility of neurological snake bites should be considered. ${ }^{23}$

In the current study, there were many cases of intentional use of poisons in the adolescent group. The quantity of intentional poison ingested was often large, and the toxicity was strong. All cases of death were in the adolescent group, and deaths were more frequent in girls than in boys. Intentional poisoning was mainly via highly toxic

Table 4 Clinical Characteristics Associated with Different Poisoning Routes (n, \%)

\begin{tabular}{|c|c|c|c|c|c|c|}
\hline $\begin{array}{l}\text { Pathways of } \\
\text { Poisoning }\end{array}$ & $\begin{array}{l}\text { Digestive } \\
\text { System }\end{array}$ & $\begin{array}{c}\text { Respiratory } \\
\text { System }\end{array}$ & $\begin{array}{c}\text { Blood Circulation } \\
\text { System }\end{array}$ & $\begin{array}{l}\text { Nervous } \\
\text { System }\end{array}$ & $\begin{array}{l}\text { Urinary } \\
\text { System }\end{array}$ & Others \\
\hline $\begin{array}{l}\text { Gastrointestinal } \\
\text { poisoning }\end{array}$ & $167 \mid(100.0)$ & $25(1.5)$ & $187(11.2)$ & $82(4.9)$ & $40(2.4)$ & $50(3.2)$ \\
\hline Inhalation poisoning & 0 & $49(100.0)$ & 0 & $49(100.0)$ & 0 & 0 \\
\hline Contact poisoning & 0 & 0 & $2 I(100.0)$ & 0 & 0 & $2 I(100.0)$ \\
\hline Animal bite stabbing & 0 & 0 & 0 & $\mathrm{II}(100.0)$ & $2(18.2)$ & $\mathrm{II}(100.0)$ \\
\hline latrogenic poisoning & 0 & 0 & 0 & $3(100.0)$ & 0 & 0 \\
\hline
\end{tabular}


Table 5 Prognosis Distributions in Poisoned Children with Different Hospital Stay Durations

\begin{tabular}{|c|c|c|c|c|c|c|}
\hline Types of Poisoning & $\leq \mathbf{3 d}$ & $4-6 d$ & 7-9d & $\geq 10 \mathrm{~d}$ & $\chi^{2}$ & $P$ value \\
\hline Pesticides & $202(30.7)$ & $314(47.6)$ & $76(I I .5)$ & $67(10.2)$ & 515.3 & $<0.0001$ \\
\hline Medicines & $468(97.7)$ & $10(2.1)$ & $\mathrm{I}(0.2)$ & 0 & & \\
\hline Food & $|4|(87.6)$ & $20(12.4)$ & 0 & 0 & & \\
\hline Rat poison & $107(98.2)$ & $2(1.8)$ & 0 & 0 & & \\
\hline Chemicals & $|2|(\mid 00.0)$ & 0 & 0 & 0 & & \\
\hline $\mathrm{CO}$ & $35(71.4)$ & $7(14.3)$ & $7(14.3)$ & 0 & & \\
\hline Alcohol & 7I(88.8) & $3(3.8)$ & $6(7.6)$ & 0 & & \\
\hline Animal bite stabbing & $9(81.8)$ & 0 & $2(18.2)$ & & & \\
\hline Other & $86(100.0)$ & 0 & 0 & 0 & & \\
\hline
\end{tabular}

pesticides, and the fatality rate was high. ${ }^{24,25}$ Some children repeatedly took poison by themselves, indicating serious mental illness and a need for professional psychological treatment. Currently, the worldwide incidence of mental health problems among adolescents is approximately $10 \%-20 \%{ }^{26}$ In the past 30 years emotional and behavioral problems have increased in children and adolescents in China, ${ }^{27}$ which has led to an increase in selfharm and suicide among adolescents. ${ }^{28}$ Self-administration of insecticides is reportedly a common way for young people to commit suicide, ${ }^{29,30}$ and it is more common in females than in males. ${ }^{31}$

In the present study, adolescent children used alcohol significantly more than children of other ages. There were more rural areas than cities, male more than female, and occasional heavy drinking was the majority. Studies indicate that adolescent drinking is closely related to family, society, school, and personal social interaction. ${ }^{32}$ It is reportedly positively correlated with parents having alcoholism, and negatively correlated with parental educational level and socioeconomic level. ${ }^{33}$ This indicates a need to promote the dangers of alcohol to family members and young people. It is forbidden to sell alcoholic beverages to young people. Alcoholic beverage advertisements should include prominent drinking hazard signs.

Spring was the most common season for acute poisonings, but there were seasonal differences between regions. ${ }^{34}$ In the current study, there were more cases of food poisoning in summer and autumn. Increased temperature causes food to spoil, and summer and autumn is also the growing season for toadstools, leading to a significant increase in toadstool poisoning. Studies indicate that if toadstool poisoning is not diagnosed and treated in time, the fatality rate is as high as $30 \%{ }^{35}$ Acute poisoning among children in southwestern China has gradually increased in the past 7 years, with the highest frequency in March, which was related to the increased use of pesticides and differences in production methods in various areas. ${ }^{36}$ The vast majority of poisonings occurred in or near the home, and most were caused by the negligence of parents or other guardians. ${ }^{37,38}$

Most hospitalizations were for less than 3 days, because of the short durations of poisoning, small doses, and timely detection and prompt medical intervention. Accordingly, most patients were cured or improved and were discharged from hospital. In the present study, the mortality rate of children with acute poisoning in southwestern China was only $1 \%$, which was likely due to timely detection and treatment. It has been reported that the mortality rate in other areas was as high as $8.5 \%{ }^{39}$ We administer conventional treatments such as gastric lavage to children with acute poisoning, and timely treatments such as hemodialysis, hemofiltration, and plasma exchange in severe cases of poisoning. The cure rate in children has been significantly improved. ${ }^{40-42}$ Extracorporeal lung membrane is under investigation for the treatment of acute poisoning, and it has proven effective in individual cases. ${ }^{43}$ In the current study, many individual family members had doubts about whether their children were experiencing toxic poisoning, which emphasizes the importance of collecting medical histories and observing the clinical manifestations in children, to facilitate comprehensive judgments. Informative follow-up of cases was difficult because most of the children recovered in hospital, and only a few patients who visited the hospital for follow-up diagnosis had relevant records. Thus, there is a lack of observational data on the long-term effects of acute poisoning on children's bodies. Most recent studies suggest that respiratory diseases and allergies (such as asthma, wheezing, coughing, acute respiratory infections, hay fever, rhinitis, eczema, chronic sputum, and lung dysfunction) may be positively correlated with the late stage of acute 
poisoning. ${ }^{44,45}$ Southwestern China is the main settlement area of the Yi ethnic group. The present study indicates that due to the different living habits of the Yi the main types of poisoning among Yi children were mistaken ingestion. They typically reside in rural areas, and the main poisons ingested were pesticides, followed by medicines and chemical agents. A large proportion of $\mathrm{Yi}$ children took the poisons themselves, which may be related to the living environment, parents, and the education level of the children. To date, few relevant studies have been conducted in this regard. ${ }^{46}$

\section{Conclusion}

The present study provides new insights into acute poisoning in children. It mainly occurs in young children and preschoolers, so it is particularly important to educate parents on the prevention of poisoning. There is a need to raise public awareness of safety precautions pertaining to the use of pesticides, insecticides, and drugs. Restrictive measures should be taken to strictly control the use and storage of pesticides, and it is recommended that the production and use of pesticides and herbicides that are highly toxic to humans be reduced, and that they be sold with more visible signs of danger on the packaging. The current study also suggests the importance of maintaining an active awareness of the mental health of young people in an effort to reduce the incidence of self-harming and suicidal behavior. Families, society, educational institutions, and medical institutions should work together to reduce the incidence of acute poisoning in children.

\section{Funding}

This work was supported by a Major Science and Technology Projects in Sichuan Province grant (grant number 2019YFS0531).

\section{Disclosure}

The authors have no conflicts of interest to declare.

\section{References}

1. Dilton RM, Silva MM, Almeida MMA, et al. Acute poisoning in children in Bahia, Brazil. Glob Pediatr Health. 2016;3:2333794X15623243. doi:10.1177/2333794X15623243

2. Kandeel F, El-Farouny R. Study of acute poisoning cases in children admitted to Menoufia Poison Control Center (MPCC) during the year 2016. Ain-Shams J Forensic Med Clin Toxicol. 2017;29(2):89-99. doi:10.21608/ajfm.2017.18213

3. Ghaleb SS, Alfatah A, Ewis L, et al. Retrospective study of acute pediatric intoxication cases by household products presented to the Poison Control Center of Ain-Shams University Hospitals. Indian J Forensic Med Toxicol. 2021;15(1):1563-1566.
4. Cunningham RM, Walton MA, Carter PM. The major causes of death in children and adolescents in the United States. $N$ Engl J Med. 2018;379(25):2468-2475. doi:10.1056/NEJMsr1804754

5. Vilaça L, Volpe FM, Ladeira RM. Accidental poisoning in children and adolescents admitted to a referral toxicology department of a Brazilian emergency hospital. Rev Paul Pediatr. 2019;38: e2018096. doi:10.1590/1984-0462/2020/38/2018096

6. Saikia D, Sharma RK, Janardhan KV. Clinical profile of poisoning due to various poisons in children of age 0-12 years. J Fam Med Prim Care. 2020;9(5):2291-2296. doi:10.4103/jfmpc.jfmpc_365_20

7. Mintegi S, Azkunaga B, Prego J, et al. International epidemiological differences in acute poisonings in pediatric emergency departments. Pediatr Emerg Care. 2019;35(1):50-57. doi:10.1097/ PEC.0000000000001031

8. Jing Z, Tao L. Study on the evolution of population concentration pattern in Southwest China based on topographical undulations. Acta Ecol Sin. 2018;38(24):8849-8860.

9. Chinese Medical Doctor Association Emergency Medical Branch. Chinese expert consensus on diagnosis and treatment of acute poisoning. Chin J Emerg Med. 2016;25(11):1361-1375.

10. Choi S. A digital application for implementing the ICD-11 traditional medicine chapter. J Integr Med. 2020;18(6):455-458. doi:10.1016/j. joim.2020.08.003

11. Azemi M, Berisha M, Kolgeci S, et al. Etiology and several sociodemographic characteristics of acute poisoning in children treated in the intensive care unit. Mater Sociomed. 2012;24(2):76-80. doi:10.5455/msm.2012.24.76-80

12. Zhu F, Wang C. Epidemiological analysis of pesticide poisoning in children aged 0-14 in Bengbu from 2007 to 2018. Chin J Sch Health. 2019;12:1210-1212.

13. Moon JM, Chun BJ, Cho YS, et al. Characteristics of emergency department presentations of pediatric poisoning between 2011 and 2016: a retrospective observational study in South Korea. Pediatr Emerg Care. 2021;37(5):e261-e268. doi:10.1097/PEC.00000 00000001668

14. Hou YH, Zhao Q, Wu YX, et al. An analysis of the clinical and epidemiological characteristics of acute poisoning patients in a general hospital. Zhonghua Lao Dong Wei Sheng Zhi Ye Bing Za Zhi. 2016;34 (7):506-509. doi:10.3760/cma.j.issn.1001-9391.2016.07.007

15. Trueblood AB, Forrester MB, Han D, et al. Pesticide-related poison center exposures in children and adolescents aged $</=19$ years in Texas, 2000-2013. Clin Toxicol. 2016;54(9):852-856.

16. Alghadeer S, Alrohaimi M, Althiban A, et al. The patterns of children poisoning cases in community teaching hospital in Riyadh, Saudi Arabia. Saudi Pharmaceut J. 2018;26(1):93-97. doi:10.1016/j. jsps.2017.10.007

17. Gummin D, Mowry J, Spyker D, et al. 2018 annual report of the American Association of Poison Control Centers' National Poison Data System (NPDS): 36th annual report. Clin Toxicol. 2019;57 (12):1220-1413. doi:10.1080/15563650.2019.1677022

18. Assaf RR, Young KD. Trends in pediatric recreational drug use and ingestions. Adv Pediatr. 2021;68:261-281. doi:10.1016/j. yapd.2021.05.011

19. Bell JC, Bentley JP, Downie C, et al. Accidental pharmacological poisonings in young children: population-based study in three settings. Clin Toxicol. 2018;56(8):782-789. doi:10.1080/ 15563650.2017.1422509

20. Mattiuzzi C, Lippi G. Worldwide epidemiology of carbon monoxide poisoning. Hum Exp Toxicol. 2020;39(4):387-392. doi:10.1177/ 0960327119891214

21. Eichhorn L, Thudium M, Jüttner B. The diagnosis and treatment of carbon monoxide poisoning. Dtsch Ärztebl Int. 2018;115(51-52):863. doi:10.3238/arztebl.2018.0863

22. Ng PCY, Long B, Koyfman A. Clinical chameleons: an emergency medicine focused review of carbon monoxide poisoning. Intern Emerg Med. 2018;13(2):223-229. doi:10.1007/s11739-018-1798-x 
23. Kumar KGS, Narayanan S, Udayabhaskaran V, et al. Clinical and epidemiologic profile and predictors of outcome of poisonous snake bites-an analysis of 1500 cases from a tertiary care center in Malabar, North Kerala, India. Int J Gen Med. 2018;11:209-216. doi:10.2147/ IJGM.S136153

24. Lavergne V, Gosselin S, Ghannoum M, et al. Extracorporeal blood purification for treating acute paraquat poisoning. Cochrane Database Syst Rev. 2018;2018(9):CD013112.

25. Elenga N, Merlin C, Le Guern R, et al. Clinical features and prognosis of paraquat poisoning in French Guiana: a review of 62 cases. Medicine. 2018;97(15):e9621. doi:10.1097/MD.0000000000009621

26. Li J, Li J, Jia R, et al. Mental health problems and associated school interpersonal relationships among adolescents in China: a cross-sectional study. Child Adolesc Psychiatry Ment Health. 2020;14(1):12. doi:10.1186/s13034-020-00318-6

27. Cui Y, Li F, Leckman JF, et al. The prevalence of behavioral and emotional problems among Chinese school children and adolescents aged 6-16: a national survey. Eur Child Adolesc Psychiatry. 2021;30 (2):233-241. doi:10.1007/s00787-020-01507-6

28. Piller HA, Ackerman JP, Spiller NE, et al. Sex-and age-specific increases in suicide attempts by self-poisoning in the United States among youth and young adults from 2000 to 2018. J Pediatr. 2019;210:201-208. doi:10.1016/j.jpeds.2019.02.045

29. Nistor N, Jitareanu C, Frasinariu OE, et al. Epidemiologic profile and triggering factors of voluntary poisoning in teenagers. Medicine. 2017;96(5):e5831. doi:10.1097/MD.0000000000005831

30. Ghanem MA, Sultan EA, Mahmoud HRG, et al. Adolescent's suicide using pesticides: risk factors and outcome prediction. Asia Pac J Med Toxicol. 2021;10(1):6-11.

31. Azab SM, Hirshon JM, Hayes BD, et al. Epidemiology of acute poisoning in children presenting to the poisoning treatment center at Ain Shams University in Cairo, Egypt, 2009-2013. Clin Toxicol. 2016;54(1):20-26.

32. Windle RC, Windle M. Adolescent precursors of young adult drinking motives. Addict Behav. 2018;82:151-157. doi:10.1016/j. addbeh.2018.03.002

33. Grevenstein D, Nikendei C, Nagy E. Alcohol use, binge drinking, and drunkenness experience in adolescence: complex associations with family, peers, social context, and risk perceptions. Subst Use Misuse. 2020;55(11):1834-1845. doi:10.1080/10826084.2020. 1766504

34. Balme KH, Roberts JC, Glasstone M, et al. Pesticide poisonings at a tertiary children's hospital in South Africa: an increasing problem. Clin Toxicol. 2010;48(9):928-934. doi:10.3109/15563650. 2010.534482
35. Trakulsrichai S, Sriapha C, Tongpoo A, et al. Clinical characteristics and outcome of toxicity from Amanita mushroom poisoning. Int J Gen Med. 2017;10:395-400. doi:10.2147/IJGM.S141111

36. Lee J, Fan NC, Yao TC, et al. Clinical spectrum of acute poisoning in children admitted to the pediatric emergency department. Pediatr Neonatol. 2019;60(1):59-67. doi:10.1016/j.pedneo.2018.04.001

37. Alhaboob AA. Sociodemographic characteristics and risk factors for childhood poisoning reported by parents at a tertiary care teaching hospital. Cureus. 2021;13(2):e13313. doi:10.7759/cureus.13313

38. National survey of drug use and health national institute on drug abuse; 2013. Available from: https://www.drugabuse.gov/drug-topics /trends-statistics/national-drug-early-warning-system-ndews/nationalsurvey-drug-use-health. Accessed August 5, 2020.

39. Hung NT, Hong TTM, Le Ngoc Duy NTT, et al. Acute poisoning in children at the Vietnam National Children's Hospital during 20172020. J Pediatr Res Pract. 2021;5(1):9-16.

40. Ghannoum M, Hoffman RS, Gosselin S, et al. Use of extracorporeal treatments in the management of poisonings. Kidney Int. 2018;94 (4):682-688. doi:10.1016/j.kint.2018.03.026

41. Li A, Li W, Hao F, et al. Early stage blood purification for paraquat poisoning: a multicenter retrospective study. Blood Purif. 2016;42 (2):93-99. doi:10.1159/000445991

42. Zhang HH, Fang Y, Ren XX, et al. Acute poisoning in children: a clinical analysis of 521 cases. Chin $J$ Prac Pediatr. 2018;33:622-625.

43. Resiere D, Kallel H, Oxybel O, et al. Clinical and epidemiological characteristics of severe acute adult poisoning cases in Martinique: implicated toxic exposures and their outcomes. Toxics. 2020;8(2):28. doi:10.3390/toxics 8020028

44. Shaffo FC, Grodzki AC, Fryer AD, et al. Mechanisms of organophosphorus pesticide toxicity in the context of airway hyperreactivity and asthma. Am J Physiol Lung Cell Mol Physiol. 2018;315(4):L485L501. doi:10.1152/ajplung.00211.2018

45. Buralli RJ, Dultra AF, Ribeiro H. Respiratory and allergic effects in children exposed to pesticides - a systematic review. Int J Environ Res. 2020;17:2740.

46. Jinrong G, Benlei Y. Development status and future thinking of Yi nationality medicine. Chin J Natl Med. 2018;07:1-2.
International Journal of General Medicine

\section{Publish your work in this journal}

The International Journal of General Medicine is an international, peer-reviewed open-access journal that focuses on general and internal medicine, pathogenesis, epidemiology, diagnosis, monitoring and treatment protocols. The journal is characterized by the rapid reporting of reviews, original research and clinical studies across all disease areas. The manuscript management system is completely online and includes a very quick and fair peer-review system, which is all easy to use. Visit http://www.dovepress.com/ testimonials.php to read real quotes from published authors. 